\title{
Utilization of cellulose microfiber from pineapple leaf as lipase immobilization support for highly retained activity, ease of separation and reusability
}

\author{
Thitinun Pradubsang $^{\mathrm{a}}$, Pranee Inprakhon ${ }^{\mathrm{b}}$, Nisa Patikarnmonthon ${ }^{\mathrm{b}}$, Taweechai Amornsakchai ${ }^{\mathrm{c}, \mathrm{d}, *}$ \\ a Materials Science and Engineering Program, Faculty of Science, Mahidol University, \\ Bangkok 10400 Thailand \\ b Department of Biotechnology, Faculty of Science, Mahidol University, Bangkok 10400 Thailand \\ c Polymer Science and Technology Program, \\ Department of Chemistry and Centre of Excellence for Innovation in Chemistry, Faculty of Science, \\ Mahidol University, Salaya, Nakhon Pathom 73170 Thailand \\ d Centre of Sustainable Energy and Green Materials, Faculty of Science, Mahidol University, Salaya, \\ Nakhon Pathom 73170 Thailand
}

*Corresponding author, e-mail: taweechai.amo@mahidol.ac.th

Received 15 Oct 2017

Accepted 18 Aug 2018

\begin{abstract}
We investigate the use of cellulose microfibre from pineapple leaf, referred to as pineapple leaf microfibre (PALMF), as a support for the immobilization of lipase AY from Candida rugosa. PALMF was produced from pineapple leaf waste with a very fine diameter of about $3 \mu \mathrm{m}$. It disperses very well in aqueous media and can easily be filtered out. PALMF in the forms of loose fibre and of mat were used. Different amounts of enzyme were immobilized on these PALMFs and tested for their hydrolytic activity. The reusability of the immobilized enzyme was also studied. The results showed that, for the selected amount of lipase used, enzyme loading and PALMF form affect the hydrolytic activity of the enzyme. Immobilized enzymes display slightly lower hydrolytic activity than the free enzyme. The activity decreases when the enzyme loading (on PALMF) is increased. Lipase AY immobilized with optimum quantity (1.37 mg/g of PALMF support) displayed a $12 \%$ drop in activity from that of free enzyme. The crowding of enzyme molecules on the PALMF surface caused steric hindrance and reduced accessibility to the active site of the enzyme. So with the suitable amount of immobilized enzyme on PALMF, reasonable hydrolytic activity together with easy separation and reusability can be obtained. This method could aid significantly the use of enzyme in industrial processes.
\end{abstract}

KEYWORDS: natural fibre, microcellulose fibre, enzyme immobilization

\section{INTRODUCTION}

Great efforts have been made to turn agricultural residues into different value-added products ${ }^{1,2}$. Using these not only provides less dependence on non-renewable resources such as petroleum, but is also better for the environment by preventing the residues cluttering up the fields. Mostly such developments have been related to the mechanical properties of polymer matrix-filler composites ${ }^{1,2}$. Other uses of agricultural residues include textile fibre $^{3}$, dye ${ }^{4}$, heavy metal or oil adsorbents ${ }^{5}$, creation of nanocellulose ${ }^{6}$ as well as feedstocks for chemicals and biofuel production ${ }^{7}$.

Most recently the use of enzymes or biocatalysts is gaining wider recognition in various fields. These offer many advantages, providing environmentally friendly procedures for several industries ${ }^{8}$. A good example of such is the hydrolysis of long chain triglycerides using lipase ${ }^{9}$. However, in industrial applications, the use of an enzyme is often restricted because of its poor stability, non-reusability, high cost of single use, and the need for product separation and purification. One method that can help solve these problems is to immobilize the enzyme on an appropriate support ${ }^{10}$. Using immobilized enzymes allows more efficient and continuous operation of the process involved. In addition, immobilized enzymes have improved catalytic activity, resistance to chemical condition, and high storage stability ${ }^{8}$. Hence the focus of this article is to investigate the advantage of enzyme immobilization and its effectiveness on a new support. Different immobilizing techniques have been used to enhance the 
properties of an immobilized enzyme ${ }^{11,12}$. Many types of supporting materials, both natural and synthetic, have been studied. These can be classified according to their shape and form, i.e., bead, particle, nanoparticle, fibrous or porous ${ }^{11,12}$. Each has its own advantages and disadvantages, depending on its original structure and properties. Nanoparticles, for example, offer very large surface areas and high mobility, but are difficult to handle and operate in a continuous process. Larger particles, on the other hand, while provide ease of handing, have low surface areas.

It is often the case that immobilized enzymes display lower activity than the free state. This is due to the greater limitation of reactant-catalyst diffusion ${ }^{13}$. One way to solve this problem is to find supports with very high surface areas, such as porous or nano-materials. These allow greater enzyme loading per unit mass of support. In the cases of porous materials and nanofibre mats, despite the increased enzyme loading capacity, the problem of limited diffusion still has to be overcome ${ }^{14}$. Nevertheless, by using various kinds of nanoparticles, high loading capacities and high catalytic activities have been achieved ${ }^{15}$. This is explained by the very effective Brownian motion of the nanoparticles in the solution ${ }^{16}$. However, in the industrial process these nanoparticle-immobilized enzymes are more difficult to be separated from the reaction mixture and this prohibits continuous operation.

Agricultural residues have been used as supports for enzyme immobilization ${ }^{17}$. However, most of these materials were either relatively large particles or fibres and did not have large surface area. In this study, we showed that pineapple leaf microfiber (PALMF), which is derived from pineapple leaf waste, offers important properties that are beneficial for both enzyme immobilizations during a catalysed reaction and for protection of the environment by making use of waste rather than allowing it to decay and emit greenhouse gases.

PALMF has a diameter of about $3 \mu \mathrm{m}$ with a polar, hydrophilic surface. It can be cut to any length. These characteristics allow it to be dispersed very well in an aqueous reaction medium, and at the same time facilitate easy product separation and continuous operation. More importantly, PALMF can easily be produced in large quantities from agricultural waste. It is anticipated that by using PALMF as the support, immobilized enzyme with high activity and ease of separation for batch operation or continuous operation would be possible. Thus it is the objective of this study to use PALMF as the support for the immobilization of enzyme. In this study Lipase AY from Candida rugosa was used as the test enzyme. The effect on the hydrolytic activity of enzyme-loaded PALMF was studied using different quantity of enzyme loadings and different forms of PALMF, i.e., loose fibres and mat. Reusability of the immobilized enzyme was also investigated.

\section{MATERIALS AND METHODS}

\section{Materials and Reagents}

Pineapple leaves were obtained from cultivation areas in Kok Kwai District, Amphoe Ban Rai, Uthai Thani Province, Thailand. Fibres were extracted from the leaves using mechanical milling method developed in our laboratory ${ }^{18}$.

Lyophilized lipase AY from Candida Rugosa, was purchased from Amano Enzyme Co., Nagoya, Japan. It has a molecular weight $60000 \mathrm{~g} /$ mol and the protein content of lipase AY was $3.10 \pm 0.04 \%$. Tributyrylglyceral (tributyrin) was purchased from Sigma-Aldrich. Folin-Ciocalteu reagent and Tris-(hydroxymethyl) methylamine were purchased from Fisher scientific UK limited, UK. Gum arabic from Acacia senegal and Vachellia (Acacia) seyal trees and BSA (Bovine serum albumin) were purchased from Sigma-Aldrich.

\section{Preparations of PALMF}

Fibres were extracted from the pineapple leaves using mechanical milling method as reported previously ${ }^{18}$. First, the leaves were cut perpendicular to their long axis to a length of $6 \mathrm{~mm}$. Chopped leaves were then ground with a laboratory disc mill, dried and sieved with a wire mesh of approximately 14 mesh. The pineapple leaf fibre (PALF) was obtained in a puffy woollen form and this was used as a precursor for the preparation of the microfiber (PALMF). PALF (100 g) was treated with 10\% (w/v) of $\mathrm{NaOH}$ solution (3 l) for $30 \mathrm{~min}$ and during this period of time, the mixture was stirred intermittently with a handheld high speed food processor (blender) for a total stirring time of approximately 15 min according to a method developed described previously $^{1,18}$. This operation breaks large fibre bundle down to elementary microfiber. PALMF was further treated by Lowry method ${ }^{19,20}$ to eliminate phenolic compounds that could interfere with protein measurement. This was done by washing with alkaline solution three times and then washing with deionized water. Then the PALMF was soaked in $20 \mathrm{mM}$ phosphate buffer ( $\mathrm{pH}$ 7.5) for $1 \mathrm{~h}$, washed three times and dried in a hot air oven at $80^{\circ} \mathrm{C}$ 
overnight.

PALF and PALMF were analysed on a Nicolet 6700 FTIR spectrometer in ATR mode. The shape and size of PALF and PALMF were observed with a scanning electron microscope (JEOL; JSM-6610LV).

\section{Procedure for immobilization of lipase}

Lipase AY was immobilized on PALMF surface as follows: A predetermined amount of lipase AY was dissolved in $20 \mathrm{mM}$ of phosphate buffer $(\mathrm{pH}$ 7.5) to give concentrations of $1.6,3.2,4.8,6.4$, and $8.0 \mathrm{mg} / \mathrm{ml} .1 \mathrm{~g}$ of PALMF was soaked into $25 \mathrm{ml}$ of these solutions, and left overnight. The solutions were decanted and washed with $25 \mathrm{ml}$ of $20 \mathrm{mM}$ of phosphate buffer ( $\mathrm{pH}$ 7.5). The supernatant and washing buffer solution were collected for the determination of residual enzyme. PALMF-immobilized AYs are designated as PALMF-AY\#1, PALMF-AY\#2, PALMF-AY\#3, PALMF-AY\#4 and PALMF-AY\#5 according to the increasing concentrations of lipase. In addition to the use of loose PALMF as described above, PALMF mat was used for solution of 1.6 and $3.2 \mathrm{mg} / \mathrm{ml}$ and the immobilized AYs are designated as PALMF-AY\#1-Mat and PALMF-AY\#2-Mat, respectively. These PALMF-AYs were dried overnight in desiccators until they were ready for use.

\section{Pure lipase AY determination}

The amount of protein in lipase AY was determined spectrophotometrically using Lowry's method ${ }^{20,21}$. Bovine serum albumin was used as the standard protein. The protein was reacted with the FolinCiocalteu reagent to produce colour solution. The measurement was made at the wavelength of $750 \mathrm{~nm}$.

The amount of lipase AY adsorbed on PALMF support or immobilized enzyme was determined from the following equation,

$$
\text { Adsorbed lipase }(\mathrm{mg} / \mathrm{g})=\frac{P_{0}-P_{1}}{m_{\text {sup }}}
$$

where $P_{0}$ is the amount of lipase AY in the initial solution (mg), $P_{1}$ is the amount of residual lipase AY (mg), and $m_{\text {sup }}$ is the weight of PALMF-AY (g).

The data obtained as above were used to the determine immobilization efficiency. That is how much of the lipase provided can be immobilized on the support.

$$
\text { Immobilization efficiency }(\%)=\frac{P_{0}-P_{1}}{P_{0}} \times 100 .
$$

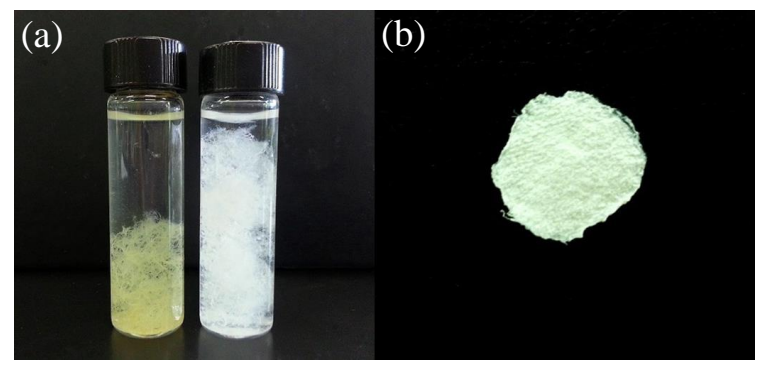

Fig. 1 Dispersion behaviour of equal amounts of (a) PALF and PALMF in distilled water and (b) PALMF-Mat.

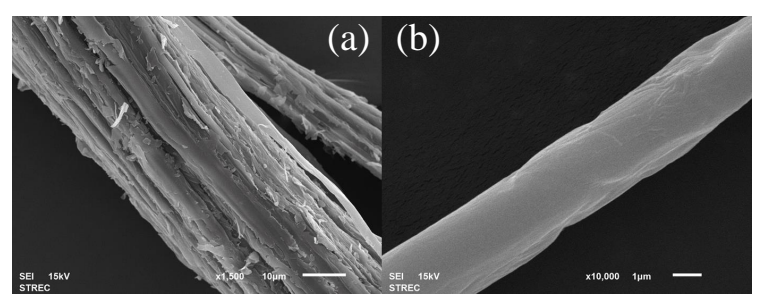

Fig. 2 Scanning electron microscopy images of (a) starting PALF and (b) PALMF obtained after treatment. Note the different magnification of the two images.

\section{Hydrolytic activity assay of free and PALMF-immobilized lipases AY}

The hydrolytic activity of both the immobilized lipase AY and the free lipase AY were measured by titration using a $\mathrm{pH}$-stat titrator (Mettler Toledo DL50). One $\mathrm{ml}$ of free lipase $\mathrm{AY}(1 \mathrm{mg} / \mathrm{ml})$ or PALMF-immobilized lipase AY with an equivalent amount of enzyme ( $1 \mathrm{mg}$ ) were dissolved in Tris-HCl buffer $\mathrm{pH}$ 7.5. Tributyrin was used as a substrate for this reaction. The total reaction mixture consisted of $116 \mu \mathrm{l}$ of tributyrin as a substrate, $4 \mathrm{ml}$ of $10 \%(\mathrm{w} / \mathrm{w})$ gum arabic solution (in Tris-HCl buffer $\mathrm{pH}$ 7.5), and lipase AY in Tris-HCl buffer $\mathrm{pH} 7.5$ (15 $\mathrm{ml}$ for free lipase AY and $16 \mathrm{ml}$ for immobilized lipase $A Y)^{22}$. It was homogenized for 1 min immediately before titration. All the titrations were carried out within $10 \mathrm{~min}$, at $40^{\circ} \mathrm{C}$ and $40 \mathrm{rpm}$ stirring speed, in triplicate. The activity of the enzymes was determined by measuring the volume of $\mathrm{NaOH}$ used to neutralize the free fatty acid released in the reaction. One unit (U) of lipase activity is defined as the amount of enzyme lipase that released $1 \mathrm{mmol}$ of fatty acid per minute under the test conditions. 


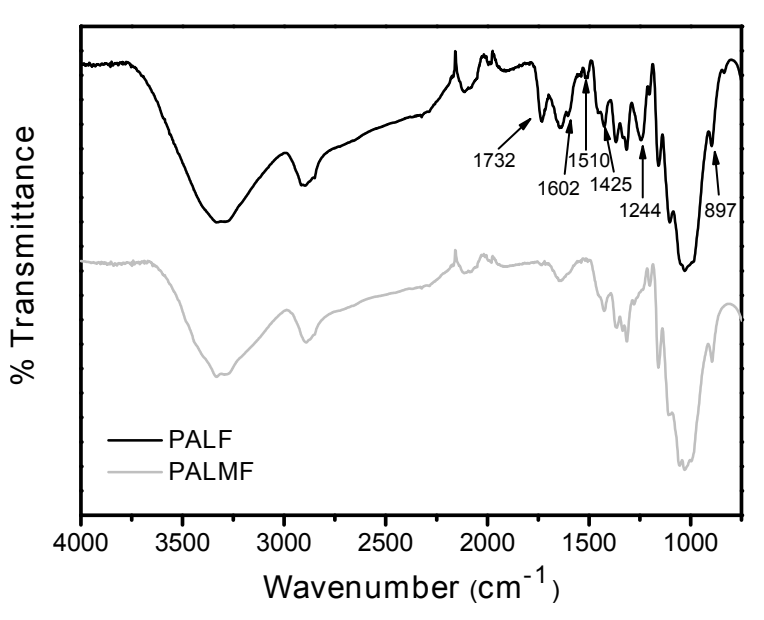

Fig. 3 FTIR spectrum of PALF and PALMF.

\section{RESULTS}

\section{Pineapple leaf fibre}

Fig. 1 displays the dispersion behaviour of the initial PALF, the pineapple leaf microfiber (PALMF) and the pineapple leaf microfiber mat (PALMF-Mat). PALMF disperses very well in water, occupying a greater volume than the starting PALF. Fig. 2 shows scanning electron microscopy images of the starting PALF and PALMF. The PALF is a bundle of many small microfibers. After treatment, the fibre bundles break down into smaller microfibers of about 3 $5 \mu \mathrm{m}$ in diameter. These have a very clean and smooth surface. The PALMF has a much greater surface area than the starting PALF. So the PALMF is more suitable than PALF for subsequent lipase immobilization.

Fig. 3 shows FTIR spectra of PALF and PALMF. The spectra display typical signals for lignocellulosic materials ${ }^{6,23}$. Only the bands that are clearly different are highlighted. The bands at 1732, 1510, and $1244 \mathrm{~cm}^{-1}$ which represent the $\mathrm{C}=\mathrm{O}$ stretching (1732 and $1510 \mathrm{~cm}^{-1}$ ) and CO stretching of acetyl group in hemicellulose (xylan) clearly disappear from PALMF spectra ${ }^{24}$. PALMF still displays signals of lignin at 1635,1505 , and $1367 \mathrm{~cm}^{-1}$ corresponding to $\mathrm{C}=\mathrm{C}$ stretching, aromatic skeletal vibration of benzene ring and $\mathrm{CH}$ bending, respectively. However, the band at 1158 and $1029 \mathrm{~cm}^{-1}$ represent the asymmetric $\mathrm{CO}-\mathrm{C}$ stretching and symmetric $\mathrm{CO}$ stretching of lignin still remained in PALMF. From the FTIR spectrum, it can be concluded that hemicellulose have been removed from PALF by washing several times with $\mathrm{NaOH}$ solution.

\section{Enzyme immobilization}

Table 1 presents the amount of enzyme immobilized on the surface of PALMF under different conditions. The immobilization efficiency can be calculated from the ratio of the amount of immobilized enzyme to the amount of initial enzyme used. The data in Table 1 illustrate that as the initial amount of crude lipase is increased, the amount of immobilized enzyme increases (0.8-2\%), whereas the immobilization efficiency drops slightly (from 73 to $58 \%$ ). This suggests that the PALMF can be used as a better enzyme support, although the amount of lipase so immobilized might reach saturation. Although the immobilization efficiency seems poorer at high lipase concentration, it is the amount of immobilized lipase that is important for the selected applications. Further, the solution remaining after washing, might be too dilute for further re-use when the initial lipase AY concentration is low.

\section{Enzymatic activity of PALMF-immobilized lipase AY}

Table 1 displays the enzymatic activity of free lipase AY and PALMF-immobilized lipase AY for tributyrin hydrolysis. The enzyme contents of each sample were kept at the equivalent amounts of $1 \mathrm{mg}$ of crude lipase or $0.031 \mathrm{mg}$ of pure lipase AY. The results indicated that the free enzyme provides the highest hydrolysis activity. For the immobilized enzyme, the lipase activity in PALMFAY\#1 is higher than that in other samples. Despite the equal total enzyme content, the activity of the enzyme decreases with increasing enzyme loading on the support. This decrease in activity might be due to the immobilization or crowding of enzyme molecules on the PALMF surface, thus causing steric hindrance and reduced accessibility of the substrate to the active enzyme site ${ }^{25,26}$.

To examine the above postulations, the enzymatic activity and the relative amount of PALMF-AY support are shown in Fig. 4. Since the relative activities and relative amounts of the different PALMF-AY samples are not the same, there are other factors to be considered. Loose PALMFs with the same content of enzyme were formed into mat, i.e., PALMF-AY\#1, and PALMF-AY\#2. Their enzymatic activities are shown in Table 1. The activities dropped from 4.10 to $1.46 \mathrm{U}$ and from 3.61 to $1.84 \mathrm{U}$ for PALMF-AY\#1 and PALMF-AY\#2, respectively. By changing the loose fibre form to mat, the activity drops significantly. Indeed PALMF-AY\#1-Mat and PALMF-AY\#2Mat swell to some extent in the solution, otherwise 
Table 1 Activity and specific activity of free and PALMF-immobilized lipase AY.

\begin{tabular}{lccccccc}
\hline Sample code & $\begin{array}{c}\text { Adsorbed } \\
\text { lipase }(\mathrm{mg} / \mathrm{g})\end{array}$ & $\begin{array}{c}\text { Immobilization } \\
\text { efficiency (\%) }\end{array}$ & $\begin{array}{c}\text { Weight } \\
\text { PALMF-AY*(mg) }\end{array}$ & $\begin{array}{c}\text { Activity } \\
(\mathrm{U})\end{array}$ & $\begin{array}{c}\text { PALMF-AY } \\
(\mathrm{U} / \mathrm{g})\end{array}$ & $\begin{array}{c}\text { Lipase AY } \\
\text { (U/mg) }\end{array}$ & $\begin{array}{c}\text { Relative } \\
\text { activity (\%) }\end{array}$ \\
\hline Free enzyme & - & - & - & 5.15 & - & 166.17 & 100.00 \\
PALMF-AY\#1 & 0.77 & 72.46 & 38.85 & 4.10 & 105.70 & 137.28 & 82.62 \\
PALMF-AY\#2 & 1.37 & 70.50 & 21.90 & 3.61 & 165.07 & 120.50 & 72.52 \\
PALMF-AY\#3 & 1.55 & 66.65 & 19.42 & 2.44 & 125.33 & 80.87 & 48.67 \\
PALMF-AY\#4 & 1.92 & 58.40 & 15.65 & 2.03 & 130.13 & 67.81 & 40.81 \\
PALMF-AY\#5 & 2.02 & 57.56 & 14.87 & 1.60 & 107.38 & 53.18 & 32.01 \\
PALMF-AY\#1-Mat & 0.77 & 72.46 & 38.85 & 1.46 & 37.68 & 48.94 & 29.45 \\
PALMF-AY\#2-Mat & 1.37 & 70.50 & 21.90 & 1.84 & 84.06 & 61.37 & 36.93 \\
\hline
\end{tabular}

"Weight of PALMF-AY that carries an equivalent amount of $1 \mathrm{mg}$ Candida rugosa crude lipase or $0.031 \mathrm{mg}$ protein.

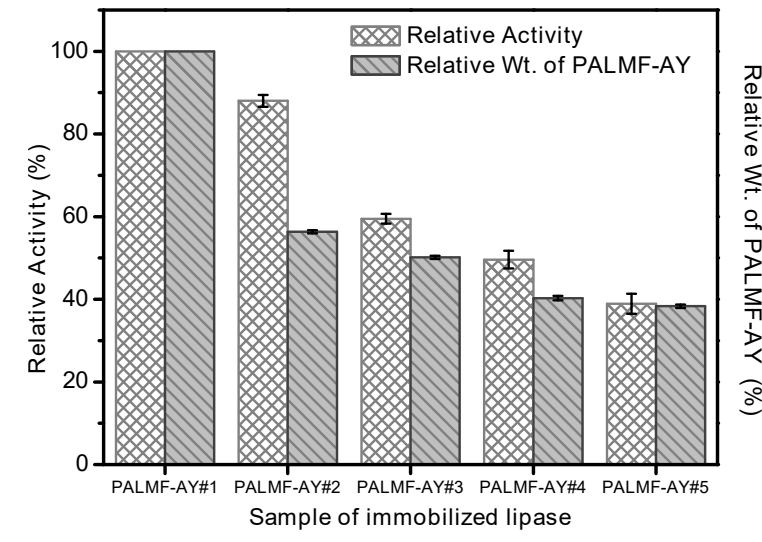

Fig. 4 Hydrolytic activity of PALMF-immobilized lipase and relative weight of PALMF-AY for each sample.

the observed activity could have been lower. These results agree well with the study of wool fibre which is well distributed in solution and exhibits a higher relative activity compared to free enzyme ${ }^{27}$. It is likely that the relatively high catalytic activity of immobilized enzyme could be attributed to the loose form of the fibre ${ }^{27}$. The observed relative activity of PALMF is $10-30 \%$ higher than the values of reported for other immobilized systems ${ }^{28,29}$.

\section{Reusability of PALMF-immobilized lipase AY}

The reusability of PALMF-immobilized lipase AY is shown in Fig. 5. The immobilized lipase AY from PALMF-AY\#2 was recycled for 4 times and the hydrolytic activity of each recycle number was observed by titration with tributyrin. The relative activity of the first use was assumed to be $100 \%$. The relative activity of each recycle number was found to drop from $100 \%$ to $65 \%, 45 \%$ and $40 \%$ for the 2 nd, $3 \mathrm{rd}$, and 4th recycles, respectively. Since lipase is physically adsorbed on the PALMF surface, it seems

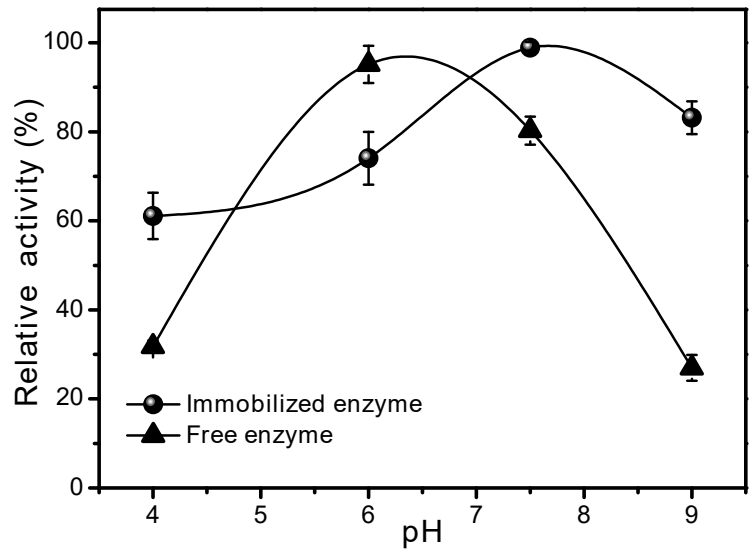

Fig. 5 Hydrolytic activity of immobilized lipase AY (PALMF-AY\#2) at pH 7.5 after each cycle of use.

that some lipase is leached out during each washing. However, it is also possible that lipase denaturation has occurred during use. Nevertheless, considering the condition employed and the fact that the relative activity appears to reach a constant value of about $40 \%$, it is very likely that lipase desorption could be the main reason for the reduced activity ${ }^{17,30}$.

\section{DISCUSSION}

It has been shown that PALMF can be used effectively as a support for the immobilization of lipase AY. As PALMF is very fine and long, it disperses well in aqueous media and covers very large volume. Reacting substrates find their way to the immobilized lipase easily, despite limited diffusion of the enzyme. As a result, PALMF-immobilized lipase AY possesses two important advantages over the free enzyme. These are the relatively high enzymatic activity arising from high volume coverage of the fibre, and its ease of separation which enables continuous operation, compared to other specific systems which 
use nanoparticles as support ${ }^{14,31}$. PALMF provides better enzymatic activity (i.e., $75 \%$ versus $50 \%$ ) as well as ease of separation.

An additional point worth considering is that the specific activity of the enzyme can be calculated from either the weight of immobilized enzyme plus support or the weight of the enzyme itself (Table 1). For the specific activity of immobilized enzyme, the peak value is seen for PALMF-AY\#2 and decreases continuously just as the relative activity. So there is an optimum enzyme loading which represents the point at which the relative activity is acceptable and the amount of support needed is not too high.

\section{CONCLUSIONS}

Pineapple leaf microfiber (PALMF), which is derived from agricultural waste in Thailand, can be used as support for lipase immobilization. This has great potential for other enzymes and catalysts in general. The very long and fine fibre structure, and so large aspect ratios, provides a large surface area for physical adsorption of lipase or any other enzymes. The approach yields higher enzymatic activity, facilitates subsequent separation and re-usage. As enzymatic processes become more widely used in industry, these immobilization methods will greatly facilitate their introduction.

Acknowledgements: This study was partially supported by Materials Science and Engineering program, the Department of Chemistry and Department of Biotechnology, and the Centre of Excellence for Innovation in Chemistry (PERCH-CIC), Faculty of Science, Mahidol University.

\section{REFERENCES}

1. Kengkhetkit N, Amornsakchai T (2014) A new approach to 'Greening' plastic composites using pineapple leaf waste for performance and cost effectiveness. Mater Des 55, 292-9.

2. Al-Oqla FM, Sapuan SM, Ishak MR, Nuraini AA (2015) Predicting the potential of agro waste fibers for sustainable automotive industry using a decision making model. Comput Electron Agr 113, 116-27.

3. Rangabhashiyam S, Anu N, Selvaraju N (2013) Sequestration of dye from textile industry wastewater using agricultural waste products as adsorbents. $J$ Environ Chem Eng 1, 629-41.

4. Sricharussin W, Ree-iam P, Phanomchoeng W, Poolperm S (2009) Effect of enzymatic treatment on the dyeing of pineapple leaf fibres with natural dyes. ScienceAsia 35, 31-6.

5. Sud D, Mahajan G, Kaur MP (2008) Agricultural waste material as potential adsorbent for sequestering heavy metal ions from aqueous solutions - a review. Bioresource Technol 99, 6017-27.
6. Sena Neto AR, Araujo MAM, Souza FVD, Mattoso LHC, Marconcini JM (2013) Characterization and comparative evaluation of thermal, structural, chemical, mechanical and morphological properties of six pineapple leaf fiber varieties for use in composites. Ind Crops Prod 43, 529-37.

7. Rout PK, Nannaware AD, Prakash O, Kalra A, Rajasekharan R (2016) Synthesis of hydroxymethylfurfural from cellulose using green processes: A promising biochemical and biofuel feedstock. Chem Eng Sci 142, 318-46.

8. Pires-Cabral P, da Fonseca MMR, Ferreira-Dias S (2010) Esterification activity and operational stability of Candida rugosa lipase immobilized in polyurethane foams in the production of ethyl butyrate. Biochem Eng J 48, 246-52.

9. Hasan F, Shah AA, Hameed A (2006) Industrial applications of microbial lipases. Enzyme Microb Technol 39, 235-51.

10. DiCosimo R, McAuliffe J, Poulose AJ, Bohlmann G (2013) Industrial use of immobilized enzymes. Chem Soc Rev 42, 6437-74.

11. Winayanuwattikun P, Piriyakananon K, Wongsathonkittikun P, Charoenpanich J (2014) Immobilization of a thermophilic solvent-stable lipase from Acinetobacter baylyi and its potential for use in biodiesel production. ScienceAsia 40, 327-34.

12. Zhang DH, Yuwen LX, Peng LJ (2013) Parameters affecting the performance of immobilized enzyme. $J$ Chem 2013, 1-7.

13. Cerovsky V, Jakubke HD (1994) Peptide synthesis catalyzed by crosslinked $\alpha$-chymotrypsin in water/dimethylformamide solvent system. Biocatalysis 11, 233-40.

14. Ye $\mathrm{P}, \mathrm{Xu} \mathrm{ZK}, \mathrm{Wu} \mathrm{J}$, Innocent C, Seta P (2006) Nanofibrous membranes containing reactive groups: Electrospinning from poly(acrylonitrile-co-maleic acid) for lipase immobilization. Macromolecules 39, 1041-5.

15. Venditti I, Palocci C, Chronopoulou L, Fratoddi I, Fontana L, Diociaiuti M, Russo MV (2015) Candida rugosa lipase immobilization on hydrophilic charged gold nanoparticles as promising biocatalysts: Activity and stability investigations. Colloids Surf B Biointerfaces 131, 93-101.

16. Jia H, Zhu G, Wang P (2003) Catalytic behaviors of enzymes attached to nanoparticles: the effect of particle mobility. Biotechnol Bioeng 84, 406-14.

17. Ittrat $\mathrm{P}$, Chacho T, Pholprayoon J, Suttiwarayanon N, Charoenpanich J (2014) Application of agriculture waste as a support for lipase immobilization. Biocatal Agric Biotechnol 3, 77-82.

18. Kengkhetkit N, Amornsakchai $\mathrm{T}$ (2012) Utilisation of pineapple leaf waste for plastic reinforcement: 1 . A novel extraction method for short pineapple leaf fiber. Ind Crops Prod 40, 55-61.

19. Lindeboom N, Wanasundara PKJPD (2007) Inter- 
ference of phenolic compounds in Brassica napus, Brassica rapa and Sinapis alba seed extracts with the Lowry protein assay. Food Chem 104, 30-8.

20. Bollag DM, Rozycki MD, Edelstein SJ (1996) Protein Methods, 2nd edn, Wiley-Liss, New York.

21. Lowry OH, Rosebrough NJ, Farr AL, Randall RJ (1951) Protein measurement with the Folin phenol reagent. J Biol Chem 193, 265-75.

22. Kaewprapan K, Tuchinda P, Marie E, Durand A, Inprakhon P (2007) pH-imprinted lipase catalyzed synthesis of dextran fatty acid ester. $J$ Mol Catal B Enzym 47, 135-42.

23. dos Santos RM, Flauzino Neto WPF, Silvério HA, Martins DF, Dantas NO, Pasquini D (2013) Cellulose nanocrystals from pineapple leaf, a new approach for the reuse of this agro-waste. Ind Crops Prod 50, 707-14.

24. Nopparut A, Amornsakchai T (2016) Influence of pineapple leaf fiber and it's surface treatment on molecular orientation in, and mechanical properties of, injection molded nylon composites. Polym Test 52, 141-9.

25. Feng X, Patterson DA, Balaban M, Emanuelsson EAC (2013) Enabling the utilization of wool as an enzyme support: Enhancing the activity and stability of lipase immobilized onto woolen cloth. Colloids Surf B Biointerfaces 102, 526-33.

26. Monier M, El-Sokkary AMA, Sarhan AA (2010) Immobilization of Candida rugosa lipase on modified natural wool fibers. React Funct Polym 70, 122-8.

27. Ye P, Xu ZK, Wu J, Innocent C, Seta P (2006) Nanofibrous poly(acrylonitrile-co-maleic acid) membranes functionalized with gelatin and chitosan for lipase immobilization. Biomaterials 27, 4169-76.

28. Tutar H, Yilmaz E, Pehlivan E, Yilmaz M (2009) Immobilization of Candida rugosa lipase on sporopollenin from Lycopodium clavatum. Int J Biol Macromol $45,315-20$.

29. Koga H, Kitaoka T, Isogai A (2012) Paperimmobilized enzyme as a green microstructured catalyst. J Mater Chem 22, 11591-7.

30. Marry JL (1985) Application of response surface methodology to optimization of glutaldehyde activation of a support for enzyme immobilization. Appl Microbiol Biotechnol 22, 88-91.

31. Jenjob S, Sunintaboon P, Inprakhon P, Anantachoke N, Reutrakul V (2012) Chitosan-functionalized poly(methyl methacrylate) particles by spinning disk processing for lipase immobilization. Carbohydr Polym 89, 842-8. 